\title{
Surgical options and results of repeated aortic root replacement for failed aortic allografts placed in childhood
}

\author{
Max B. Mitchell, MD \\ David N. Campbell, MD ${ }^{\mathrm{a}}$ \\ Deborah A. Bishop, BS ${ }^{\text {a }}$ \\ Todd Mackenzie, $\mathrm{PhD}^{\mathrm{b}}$ \\ David R. Clarke, $\mathrm{MD}^{\mathrm{a}}$
}

From the Division of Cardiothoracic Surgery $^{\mathrm{a}}$ and the Department of Preventative Medicine and Biometrics, ${ }^{\mathrm{b}}$ University of Colorado Health Sciences Center and The Children's Hospital, Denver, Colo.

Read at the Twenty-seventh Annual Meeting of The Western Thoracic Surgical Association, San Diego, Calif, June 20-23, 2001

Received for publication June 28, 2001; revisions requested Oct 10,2001; revisions received Dec 4, 2001; accepted for publication Dec 18, 2001.

Address for reprints: Max B. Mitchell, MD, The Children's Hospital, 1056 E 19th Ave, B200. Denver, CO 80218 (E-mail: mitchell.max@tchden.org).

J Thorac Cardiovasc Surg 2002;124:459-70

Copyright () 2002 by The American Association for Thoracic Surgery

0022-5223/2002 $\$ 35.00+0 \quad \mathbf{1 2 / 6 / 1 2 2 5 4 7}$

doi:10.1067/mtc.2002.122547
Objectives: This report reviews our experience with repeated aortic root replacement after failure of cryopreserved aortic allografts placed during childhood and compares replacement with aortic allografts, pulmonary autografts, and mechanical valved conduits in these patients.

Methods: This was a retrospective analysis of all such patients from 1986 through May 2001.

Results: There were 25 operations ( 11 aortic allografts, 9 pulmonary autografts, and 5 mechanical valved conduits) among 23 patients. The mean time to reoperation was 6.3 years. There were 2 in-hospital deaths $(8 \%, 1$ patient with a pulmonary autograft and 1 with a mechanical valved conduit). There were 2 early nonfatal valve-related events ( 1 patient with an aortic allograft and 1 with a pulmonary autograft). There were no late valve-related deaths and 2 late non-valve-related deaths of patients with aortic allografts placed. No variable predicted early death or early valve-related event. No differences in preoperative characteristics, hospital variables, early outcomes, or late outcomes were detected among the groups. Overall, 19 patients are alive (18 in New York Heart Association functional class I and 1 in New York Heart Association functional class III) at a mean follow-up of 49 months. Two late aortic allograft failures necessitated reoperation. All patients with successful pulmonary autografts had excellent autograft function at a mean follow-up of 68 months. All early survivors with mechanical valved conduits are alive and free of valve-related events (mean follow-up 71 months). Five-year freedoms from valve-related death or event (Kaplan-Meier) were $84 \%$ for all patients, $91 \%$ for aortic allografts, $78 \%$ for pulmonary autografts, and $80 \%$ for mechanical valved conduits (no statistically significant group differences by log-rank test).

Conclusions: Replacement of cryopreserved aortic root allografts placed during childhood is safe. Five-year pulmonary autograft durability is excellent, although the risk of early failure may be increased. Differences in 5-year conduit longevity were not detectable.

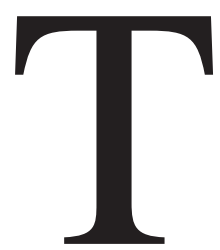

he management of aortic valve disease in children is challenging. Multilevel left ventricular outflow tract (LVOT) pathology, additional congenital heart lesions, smaller patient size with growth requirements, and difficulties with anticoagulation add increased complexity in treating children relative to treating adults. In 1987 Clarke and associates ${ }^{1}$ introduced extended aortic root replacement with cryopreserved aortic allografts for the treatment of complex LVOT obstruction in children (Figure 1). ${ }^{2}$ This procedure combines the concept of aortoventriculoplasty previously described by Konno and colleagues ${ }^{3}$ and Rastan and Koncz ${ }^{4}$ that featured total allograft aortic root replacement with direct coronary reimplantation, 


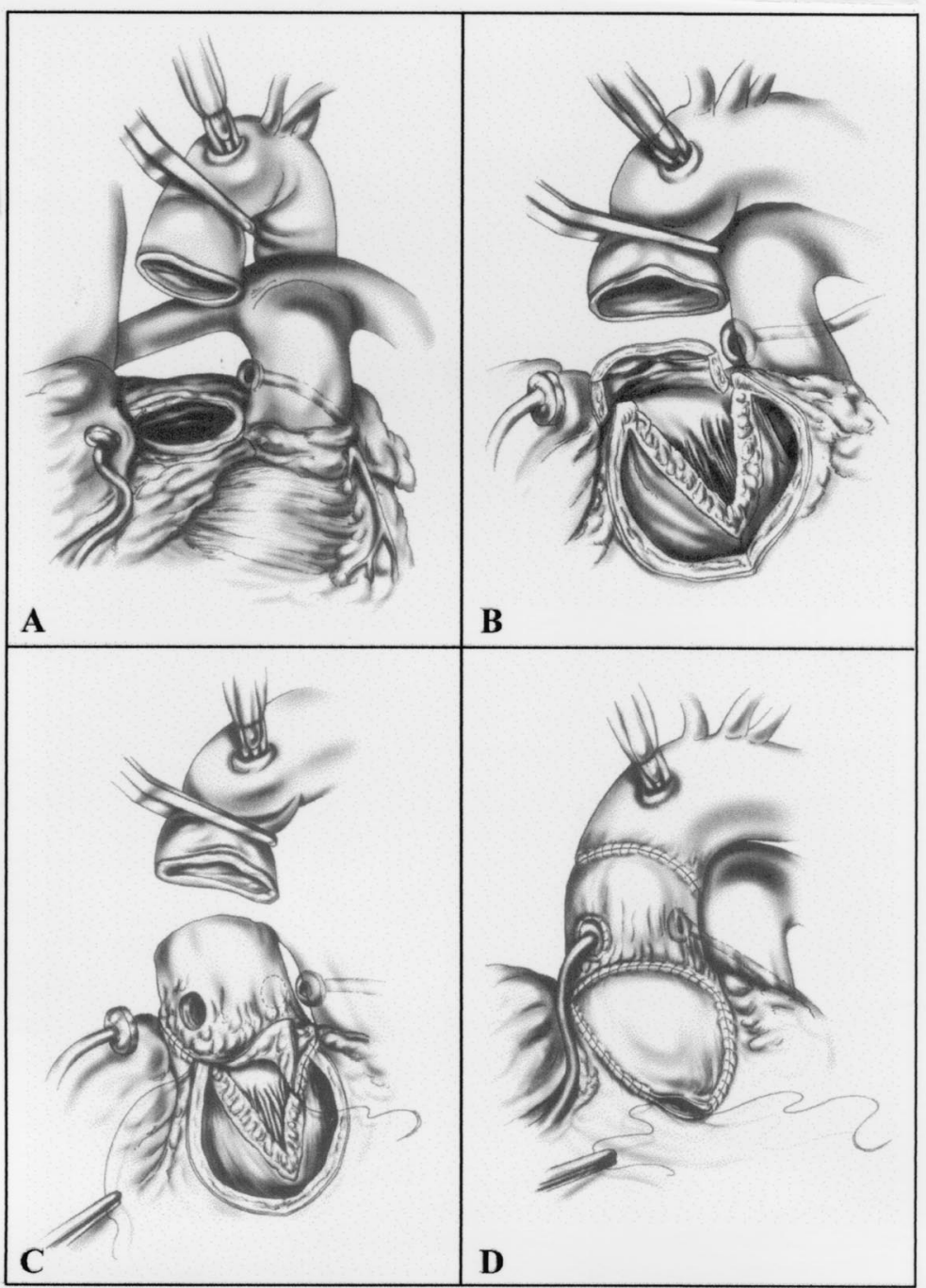

Figure 1. A, Extended aortic root replacement begins with excision of aortic root and preparation of coronary buttons. B, Oblique incision is made in right ventricle just below pulmonary valve, and this incision is joined by incision through aortic valve anulus into interventricular septum. C, Aortic root is replaced with aortic allograft with attached allograft anterior mitral leaflet used to close interventricular septum. D, Right ventricular incision is closed with separate patch to prevent obstruction. Adapted with permission from Mitchell MB, Campbell DN, Bishop DA, Clarke DR. Aortic allografts for left ventricular outflow tract replacement in children. In: Williams WG, editor. Pediatric cardiac surgery annual of the seminars in thoracic and cardiovascular surgery, vol 3. Philadelphia: WB Saunders; 2000. p. 156, 157, 158, 159.

as reported by Somerville and Ross. ${ }^{5}$ Subsequently, modified extended aortic root replacement was developed for patients with severe aortic valve and ascending aortic hypoplasia with or without interrupted aortic arch. ${ }^{6}$ The modified procedure combines extended aortic root replacement, subcoronary closure of the aorta, side-to-side anastomosis of the ascending aorta to the allograft, and anastomosis of the distal allograft to the descending aorta. These techniques enlarge the LVOT, facilitating treatment of annular hypoplasia as required and allowing placement of larger allo- grafts in small children, providing for somatic growth. Significant advantages of allografts particularly important in children are the low risk of thromboembolism, freedom from the need for anticoagulation, excellent hemodynamic performance, low risk of endocarditis, and the range of size availability. Unfortunately, the longevity of aortic allografts placed in children has been limited by tissue degeneration (Figure 2), and reoperation appears inevitable in surviving patients. 7,8

Recent reports indicate that a repeated operation on the 


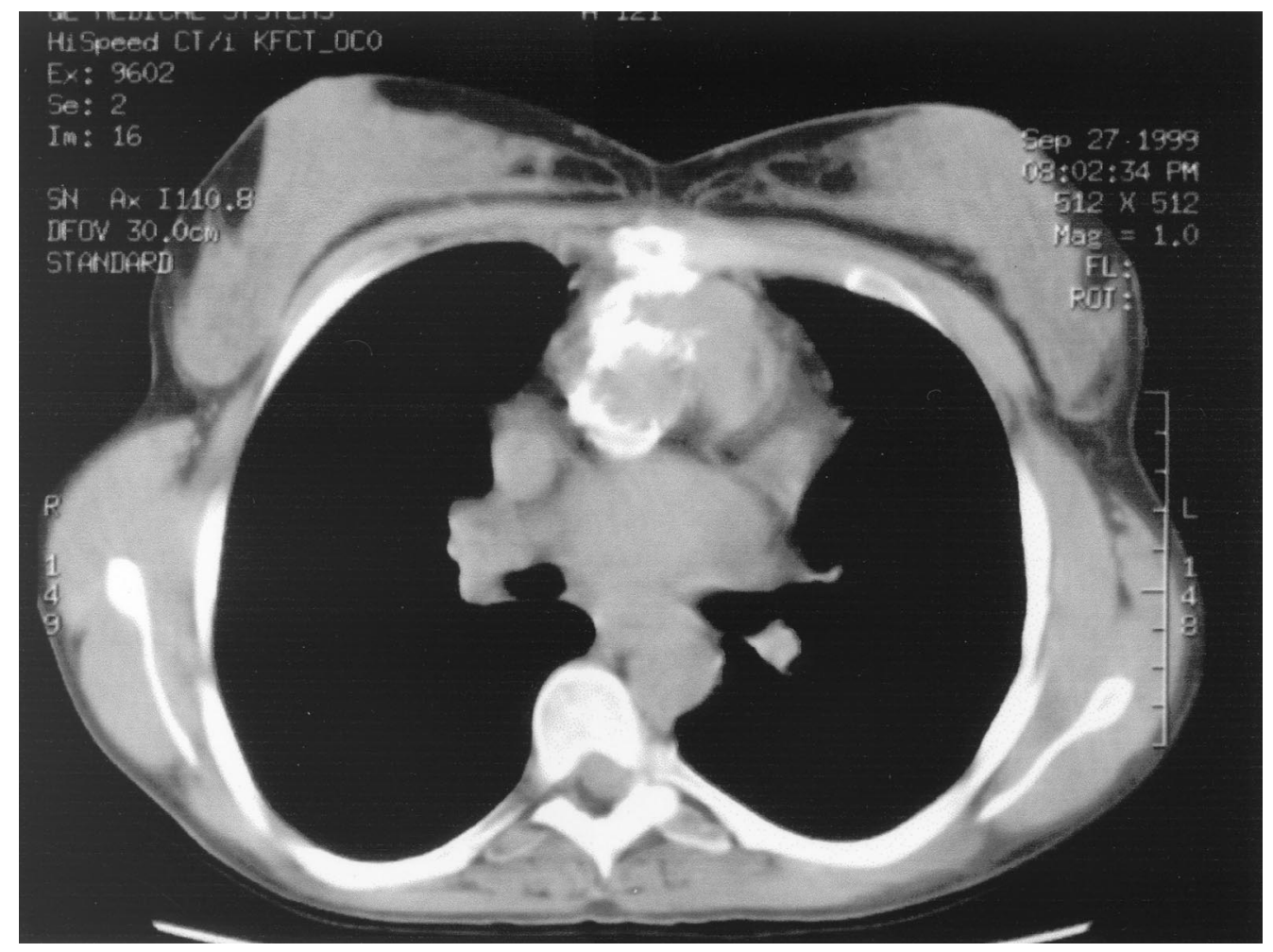

Figure 2. Thoracic computed tomographic scan 12 years after previous extended aortic root replacement with cryopreserved aortic allograft. There is severe allograft calcification. Note proximity of densely calcified RVOT patch to posterior table of sternum.

aortic root or ascending aorta after previous aortic root replacement is feasible with acceptable operative mortality in adult patients. ${ }^{9-12}$ There are no reports addressing repeated aortic root replacement in children who have undergone previous aortic root replacement with aortic allografts or other conduit options. Marked calcific degeneration of cryopreserved aortic allografts combined with a right ventricular incision and patch enlargement of the infundibulum introduce difficult technical issues when a repeated aortic root replacement is required after extended aortic root replacement. ${ }^{8}$

The purposes of this study were to review early and late results of repeated aortic root replacement after previous aortic allograft placement in children and to compare the early and late results of three conduit options used for these patients: cryopreserved aortic allograft, pulmonary autograft, and mechanical valved conduit.

\section{Methods \\ Patients}

All patients in our center who required explantation of a cryopreserved aortic allograft previously used for aortic root replacement and inserted before the age of 18 years were identified. Between October 1986 and May 2001, a total of 25 repeated aortic root replacements were performed in 23 patients meeting these criteria.
Two patients underwent third aortic root replacements after placement of a second aortic allograft. For purposes of analysis, follow-up for the first reoperation was terminated at the time of second allograft explantation for these 2 patients, and the third aortic root replacement was considered separately. Inpatient and outpatient medical records of all patients were retrospectively reviewed. Telephone interviews were conducted with patient families or the patient's primary care physician. No patients were unavailable for follow-up. There were 17 male and 6 female patients. The mean age at reoperation was $12.4 \pm 7.4$ years, with a mean interval to reoperation of $6.3 \pm 3.9$ years. The mean weight at reoperation was $38.6 \pm 23.4 \mathrm{~kg}$. Body weight increased by a mean factor of $2.2 \pm 0.9$ between the previous aortic root replacement and reoperation. The initial aortic root replacement was extended aortic root replacement in 18 cases, modified extended aortic root replacement in 3 cases, and standard aortic root replacement in 4 cases.

The primary indication for the initial aortic root replacement was LVOT obstruction in 18 cases, severe aortic insufficiency in 3 cases, truncal valve insufficiency in 1 case, and prosthetic valve malfunction in 1 case. The mean number of sternotomies before repeated aortic root replacement was $2.3 \pm 0.1$. Significant allograft insufficiency was present in 24 cases. Table 1 details the indications for repeated aortic root replacement. Cases were grouped according to the three conduit choices used: cryopreserved aortic allograft, $\mathrm{n}=11$, pulmonary autograft, $\mathrm{n}=9$, and 
TABLE 1. Indications for repeated aortic root replacement

\begin{tabular}{lr}
\hline Indication & No. \\
\hline Severe allograft aortic insufficiency & 16 \\
Combined allograft aortic insufficiency and aortic & 8 \\
stenosis & \\
Severe allograft aortic stenosis & 1 \\
\hline
\end{tabular}

mechanical valved conduit, $\mathrm{n}=5$. Concomitant procedures were required in 8 cases (Table 2 ).

\section{Surgical Technique}

Repeated sternotomy was attempted before heparinization in all cases. Prophylactic peripheral vessel exposure was achieved before sternotomy in selected cases on the basis of preoperative radiographic studies. Bicaval and ascending aortic cannulations were performed, and a left ventricular vent was placed through the right superior pulmonary vein left atrial confluence. Moderate hypothermic perfusion with cold blood retrograde cardioplegia was used in most cases. After cardioplegic arrest, the aorta was transected at the previous distal suture line, and the allograft was removed. Coronary buttons were prepared, and all calcified allograft tissue was removed from the buttons. The proximal allograft valve was excised from the LVOT. In the case of previous extended aortic root replacement, the ventricular septal defect (VSD) and right ventricular outflow tract (RVOT) patches were excised and replaced with polytetrafluoroethylene patches* as required. All aortic allograft group cases used cryopreserved aortic allografts (CryoLife, Inc, Kennesaw, Ga), with direct coronary reimplantation according to previously published techniques. ${ }^{1,8}$ After disassembly of the aortic root and coronary artery button preparation, careful autograft procurement was accomplished, and total root replacement was performed with direct coronary reimplantation in all pulmonary autograft group cases. The RVOT was reconstructed with a cryopreserved pulmonary allograft (CryoLife) in all pulmonary autograft group patients. In the mechanical valved conduit group, St Jude Medical mechanical valved conduits (St Jude Medical, Inc, St Paul, Minn) were used in 4 cases and a Medtronic Hall valved conduit (Medtronic, Inc, Minneapolis, Minn) was used in 1 case. In the mechanical valved conduit group, direct coronary button reimplantation was used in 3 cases and the Cabrol modification with a polytetrafluoroethylene conduit was used twice. ${ }^{13}$ Intraoperative transesophageal echocardiography was used in all cases after 1993.

\section{Definitions and Statistical Methods}

Postoperative valve-related mortality and morbidity are reported according to previously established guidelines. ${ }^{14}$ Prolonged mechanical ventilation was defined as ventilation in excess of 48 hours. Analyses of possible predictors of both early and late valve-related events were performed with the Cox proportionalhazards model. Patients who underwent initial modified extended aortic root replacement were included with those who underwent extended aortic root replacement for purposes of determining

* Gore-Tex, registered trade name of W.L. Gore \& Associates, Inc, Flagstaff, Ariz.
TABLE 2. Concomitant procedures

\begin{tabular}{lc}
\hline Procedure & No. \\
\hline Pulmonary allograft RVOT repeated replacement & 1 \\
Patch closure of LVOT pseudoaneurysm & 1 \\
Aortic arch replacement & 1 \\
Closure of residual VSD & 1 \\
Aortic anulus plication & 1 \\
Placement of left ventricular assist device & 1 \\
Epicardial to endocardial pacer conversion & 1 \\
Splenectomy for abscess & 1
\end{tabular}

whether the type of previous aortic root replacement (extended vs standard) was a risk factor for early death or valve-related event. Comparisons of categoric variables between groups were done with the $\chi^{2}$ test or the Fisher test, and continuous variables were compared between groups with the Wilcoxon rank-sum test and the Kruskal-Wallis test. Early deaths were excluded in the calculation of hospital length of stay. Freedom from valve-related death or event was estimated by the Kaplan-Meier method, and comparisons among groups were made with the log-rank test. All statistical analyses were performed with S Plus version 4.5 (Mathsoft, Inc, Seattle, Wash).

\section{Results}

\section{Operative Mortality}

There were 2 operative deaths in this series, yielding an operative mortality of $8 \%$. All remaining patients were discharged alive. Both deaths occurred on the day of operation. In 1 case the aortic allograft was entered during resternotomy. Massive hemorrhage occurred, and emergency groin cannulation was complicated by previously undiagnosed unilateral ileofemoral venous occlusion on the side of the initial attempt at peripheral cannulation. After establishment of cardiopulmonary bypass, sternotomy was completed, and the injury was controlled. A mechanical valved conduit was inserted, but prolonged hypoperfusion caused irreversible myocardial injury. The patient could not be weaned from bypass and died in the operating room. The second patient underwent a Ross procedure. There were extensive adhesions in the region of the right ventricular infundibulum and proximal main pulmonary artery. At the time of autograft harvest, there was a minimal amount of infundibular muscle below the pulmonary valve leaflet insertion site adjacent to a heavily calcified RVOT patch that had been constructed with aortic allograft tissue at the time of the original extended aortic root replacement. The autograft was inserted, but the proximal autograft suture line dehisced at this site, causing major hemorrhage after weaning from bypass. The autograft was replaced with an aortic allograft. The total myocardial ischemic time was 333 minutes, and the patient could not be weaned from bypass. A left ventricular assist device was placed, but the patient died shortly after transfer to the intensive care unit. 


\section{Operative and Hospital Courses}

Resternotomy was accomplished uneventfully in 21 of 25 cases. There were 2 aortic injuries resulting in 1 operative death, as noted previously. Emergency peripheral cannulation without previous peripheral vessel exposure was required in both of these cases. Prophylactic peripheral vessel exposure was performed before sternotomy in 3 cases, and peripheral cannulation was required in 2 of these cases after densely adherent RVOT patches were disrupted. The mean cardiopulmonary bypass time was 254 minutes (range 108757 minutes). The mean total aortic occlusion time was 135 minutes (range 49-333 minutes).

No patient required reoperation for bleeding, and there were no conduction tissue injuries. Thirteen patients had no complications. Excluding the 2 early deaths, 13 complications occurred in the remaining 10 cases (Table 3). Four major nonfatal complications occurred in 3 patients. One patient had aortic allograft entry during resternotomy, as described previously, and survived without adverse sequelae. One patient had early autograft insufficiency necessitating reoperation. One patient had mediastinitis necessitating operative débridement, and allograft endocarditis subsequently developed and was treated medically. The median hospital stay of survivors was 8 days, and 17 patients were discharged within 10 days.

\section{Pathology}

At the time of surgery, porcelainlike allograft walls and valve leaflets with densely calcified excrescences were present in most cases. Pathologic reports were available for 22 of the 25 explanted aortic allografts. In 20 cases, devitalized elastic tissue with mural allograft calcification and fibrosis were identified histologically. Few or no inflammatory cells were noted in all these cases. In the remaining 2 cases, heavy inflammatory cell infiltrates were present. One 4-month-old infant required reoperation 4 months after modified extended aortic root replacement because of severe allograft insufficiency and distal allograft stenosis. The allograft cusps were pliable, but there was central absence of leaflet coaptation. Histologic examination revealed no calcification and a dense non-T cell lymphocytic infiltrate. In the remaining case, Candida tropicalis allograft endocarditis and a residual VSD necessitated repeated extended aortic root replacement 4 months after the previous operation. Leaflet vegetations with no evidence of calcification were noted at operation. Pseudohyphae and dense inflammatory cell infiltrates without calcification were identified at histologic examination.

\section{Early Failure of Replacement Valves}

Three early valve failures occurred. Intraoperative disruption of the proximal autograft suture line occurred in 1 case, resulting in early death as noted previously. A patient un-
TABLE 3. Complications among survivors

\begin{tabular}{lr}
\hline Complication & No. \\
\hline None & 13 \\
Prolonged ventilation & 3 \\
Cardiovascular injury during resternotomy & 3 \\
Pulmonary artery injury requiring reconstruction & 1 \\
Protamine reaction & 1 \\
Early reoperation (autograft failure) & 1 \\
Early allograft endocarditis & 1 \\
Mediastinitis & 1 \\
Renal insufficiency & 1 \\
Delayed pneumothorax & 1 \\
\hline
\end{tabular}

dergoing the Ross procedure had moderate autograft insufficiency that was detected on postoperative day 3. Intraoperative transesophageal echocardiography had demonstrated only trace autograft insufficiency. Moderate autograft insufficiency persisted, and replacement with an aortic allograft was performed on postoperative 6 . At reoperation, no structural autograft damage was identified, but the entire autograft was markedly edematous. This patient recovered uneventfully. In the third case, early allograft endocarditis was diagnosed on postoperative day 24 . This child was born with truncus arteriosus and underwent total repair with a pulmonary allograft RVOT reconstruction, a subsequent standard allograft aortic root replacement after the development of truncal valve insufficiency, and a third operation for replacement of the pulmonary allograft inserted at the initial total repair. At the time of repeated aortic root replacement, bilateral outflow tract replacements with allografts were performed. The patient had mediastinitis necessitating operative débridement and antibiotic therapy. The child subsequently had Candida albicans septicemia with aortic insufficiency, and a presumptive diagnosis of endocarditis was made. Further reoperation was refused, and the child was treated intravenously with amphotericin B. The child survived and is currently in New York Heart Association (NYHA) functional class III with severe aortic allograft insufficiency at 48 months of follow-up.

According to univariable analysis, age, weight, type of original aortic root replacement, conduit type at repeat aortic root replacement, interval to reoperation, number of previous sternotomies, cardiopulmonary bypass time, and aortic occlusion time were not predictive of early death or early valve-related event. Only cardiopulmonary bypass time approached statistical significance $(P=.09)$.

\section{Group Variables}

Characteristics of the three operative groups are given in Table 4. Although there were no detectable differences in preoperative or operative variables among groups at the $95 \%$ confidence level, the small number of patients in each 
TABLE 4. Group variables

\begin{tabular}{|c|c|c|c|}
\hline & $\begin{array}{l}\text { Aortic allograft } \\
\text { group }(n=11)\end{array}$ & $\begin{array}{l}\text { Pulmonary autograft } \\
\text { group }(\mathrm{n}=9)\end{array}$ & $\begin{array}{l}\text { Mechanical valved } \\
\text { conduit group }(n=5)\end{array}$ \\
\hline Age (y) & $10.2(0.3-19.3)$ & $13.0(3.9-23.4)$ & $16.1(3.3-23.3)$ \\
\hline Weight (kg) & $31.8(4.0-67.8)$ & $39.3(15.0-70.3)$ & $52.5(11.0-81.0)$ \\
\hline Previous sternotomies & $2.0(1.0-4.0)$ & $2.2(1.0-3.0)$ & $3.2(2.0-5.0)$ \\
\hline Interval to reoperation (y) & $5.9(0.2-12.7)$ & $6.7(3.3-12.6)$ & $6.3(3.1-11.6)$ \\
\hline Explanted allograft size (mm) & $16.5(11.0-22.0)$ & $18.4(12.0-22.0)$ & $19.4(13.0-22.0)$ \\
\hline Cardiopulmonary bypass time (min) & $206(108-315)$ & $286(166-757)$ & $282(149-403)$ \\
\hline Aortic occlusion time (min) & $114(58-158)$ & $169(98-333)$ & $119(49-225)$ \\
\hline Median hospital stay (d) & $11(4-49)$ & $5.5(4-13)$ & $8(5-11)$ \\
\hline Total early deaths (No.) & $0(0 \%)$ & $1(11 \%)$ & $1(20 \%)$ \\
\hline Total early valve failures (No.) & $1(9 \%)$ & $1(11 \%)$ & $0(0 \%)$ \\
\hline
\end{tabular}

All values reported as mean and range unless number of patients is indicated.

group limits the ability to distinguish differences, and actual differences among groups cannot be excluded.

\section{Late Deaths and Valve-Related Events}

There were no late valve-related deaths in any group. There were 2 late deaths in the aortic allograft group (Table 5, patients 1 and 7). Autopsies revealed no evidence of valvular dysfunction in either case. There were no late deaths in the pulmonary autograft and mechanical valved conduit groups. There were 2 late valve failures in the aortic allograft group, each necessitating a third aortic root replacement (Table 5, patients 2 and 5). There have been no late valve failures or valve-related events in the pulmonary autograft and mechanical valved conduit groups. Age at reoperation, weight, type of original aortic root replacement, conduit type at repeated aortic root replacement, interval to reoperation, and number of previous sternotomies were not predictive of late valve-related events.

\section{Late Outcomes}

Nineteen of the 23 patients are alive (Table 5). Eighteen patients are in NYHA class I, and 1 patient is in NYHA class III. The mean follow-up time for all patients was 49 months. The 5-year estimated freedom from valve-related death or event for the entire series was $84 \%$ (Figure 3). Excluding operative deaths, the 5-year freedom from valverelated death or event was $91 \%$ for the entire series. Mean follow-up times for the aortic allograft, pulmonary autograft, and mechanical valved conduit groups were 42, 53, and 57 months, respectively. The 5-year estimated freedoms from valve-related death or event for the aortic allograft, pulmonary autograft, and mechanical valved conduit groups were $91 \%, 78 \%$, and $80 \%$, respectively. No differences in estimated freedoms from valve-related death or event were detected among the three groups (Figure 4).

Of 10 patients in the aortic allograft group (11 operations), 8 are alive. As noted previously, 1 of these patients was later treated with a third allograft and 1 patient under- went subsequent conversion to a mechanical valve. Thus 7 repeated allografts are currently under follow-up in the aortic allograft group. One patient is in NYHA class III after early development of endocarditis (postoperative day 24) and remains alive without operation, as noted previously. Of the remaining 6 patients in the allograft group, all are in NYHA class I at a mean follow-up of 46 months. Echocardiographic examination of allograft function has revealed trace or no allograft insufficiency in 3 cases, mild insufficiency in 2 cases, and mild insufficiency with mild stenosis in 1 case.

All pulmonary autograft group survivors remain alive in NYHA class I. All patients discharged after successful Ross procedures $(n=7)$ have stable autograft function at a mean follow-up of 68 months. On echocardiography, 2 autografts have trace insufficiency, 4 have mild insufficiency, and 1 has mild insufficiency and mild stenosis. There have been no RVOT allograft replacements among the 7 patients who had successful Ross procedures. The other surviving patient who required early autograft replacement with an aortic allograft has normal valve function at 49 months of follow-up but required RVOT allograft replacement at 12 months for severe pulmonary insufficiency.

The 4 mechanical valved conduit group patients who survived reoperation remain alive in NYHA class I. There have been no late valve-related complications in the mechanical valved conduit group at a mean follow-up of 71 months.

\section{Discussion}

There is no ideal solution for children requiring primary aortic valve replacement. After the introduction of the extended aortic root replacement technique, allograft replacement of the aortic valve became a commonly used option in many pediatric centers. Follow-up now indicates that surviving children will inevitably require reoperation. ${ }^{8}$ The current series demonstrates that reoperation after previous allograft standard or extended aortic root replacement per- 
TABLE 5. Patient outcomes

\begin{tabular}{|c|c|c|c|c|c|}
\hline Case & Sex & $\begin{array}{l}\text { Age at previous } \\
\text { operation (y) }\end{array}$ & Indication for reoperation & $\begin{array}{l}\text { Age at } \\
\text { reoperation } \\
\text { (y) }\end{array}$ & Outcome \\
\hline \multicolumn{6}{|c|}{ Aortic allograft group ( $n=11)$} \\
\hline 1 & $\mathrm{~F}$ & 0 (neonatal) & $\begin{array}{l}\text { Allograft endocarditis, aortic } \\
\text { insufficiency }\end{array}$ & 0.3 & Non-valve-related late death at $11.9 \mathrm{mo}$ \\
\hline $2^{*}$ & $\mathrm{~F}$ & 1 & Allograft aortic insufficiency & 1.7 & $\begin{array}{l}\text { Valve failure at } 96.3 \mathrm{mo} \text {; reoperation third } \\
\text { aortic allograft }\end{array}$ \\
\hline $5 \dagger$ & M & 14.7 & $\begin{array}{l}\text { Allograft endocarditis, aortic } \\
\text { insufficiency, residual VSD }\end{array}$ & 15.1 & $\begin{array}{l}\text { Valve failure at } 73.0 \text { mo, reoperation with } \\
\text { mechanical valved conduit }\end{array}$ \\
\hline 7 & M & 0.003 & Allograft aortic insufficiency & 0.3 & Non-valve-related late death at $2.3 \mathrm{mo}$ \\
\hline 8 & M & 6.5 & $\begin{array}{l}\text { Allograft endocarditis, aortic } \\
\text { insufficiency }\end{array}$ & 13.7 & $\begin{array}{l}\text { Mild aortic insufficiency and mild aortic } \\
\text { stenosis at } 86.4 \text { mo }\end{array}$ \\
\hline 9 & M & 11.5 & Allograft aortic insufficiency & 19.3 & Mild aortic insufficiency at 60.7 mo \\
\hline 14 & M & 2 & Allograft aortic insufficiency & 10.9 & No aortic insufficiency at $52.1 \mathrm{mo}$ \\
\hline $15^{*}$ & $\mathrm{~F}$ & 1.7 & Allograft aortic insufficiency & 9.7 & Mild aortic insufficiency at $49.7 \mathrm{mo}$ \\
\hline 16 & $\mathrm{M}$ & 0.5 & $\begin{array}{l}\text { Allograft aortic insufficiency, } \\
\text { allograft pulmonary } \\
\text { insufficiency }\end{array}$ & 9.7 & $\begin{array}{l}\text { Valve failure endocarditis at } 0.8 \mathrm{mo} \text {, severe } \\
\text { aortic insufficiency at } 44.2 \mathrm{mo}\end{array}$ \\
\hline 24 & $\mathrm{~F}$ & 6.6 & Allograft aortic insufficiency & 16.8 & No aortic insufficiency at $2.7 \mathrm{mo}$ \\
\hline 25 & $\mathrm{M}$ & 2.3 & $\begin{array}{l}\text { Allograft aortic stenosis, aortic } \\
\text { insufficiency, arch obstruction }\end{array}$ & 15 & Trace aortic insufficiency at 1.4 mo \\
\hline \multicolumn{6}{|c|}{ Pulmonary autograft group ( $\mathrm{n}=9$ ) } \\
\hline 4 & $\mathrm{M}$ & 0.6 & $\begin{array}{l}\text { Allograft aortic insufficiency, } \\
\text { mild aortic stenosis }\end{array}$ & 3.9 & $\begin{array}{l}\text { Mild neoaortic insufficiency, mild } \\
\text { pulmonary stenosis and pulmonary } \\
\text { stenosis and pulmonary insufficiency at } \\
125.1 \text { mo }\end{array}$ \\
\hline 6 & M & 0.3 & $\begin{array}{l}\text { Allograft aortic insufficiency, } \\
\text { mild aortic stenosis }\end{array}$ & 4.1 & $\begin{array}{l}\text { Mild neoaortic insufficiency and neoaortic } \\
\text { stenosis, moderate pulmonary } \\
\text { insufficiency and pulmonary stenosis at } \\
115.2 \text { mo }\end{array}$ \\
\hline 10 & M & 3.7 & $\begin{array}{l}\text { Allograft aortic insufficiency, } \\
\text { aortic stenosis }\end{array}$ & 8.2 & $\begin{array}{l}\text { Trace neoaortic insufficiency, moderate } \\
\text { pulmonary insufficiency, mild pulmonary } \\
\text { stenosis at } 58.2 \text { mo }\end{array}$ \\
\hline 11 & M & 4.4 & Allograft aortic insufficiency & 8.1 & $\begin{array}{l}\text { Early reoperation at } 0.2 \text { mo for neoaortic } \\
\text { insufficiency }\end{array}$ \\
\hline 12 & M & 9.8 & Allograft aortic stenosis & 14.4 & $\begin{array}{l}\text { Mild neoaortic insufficiency, moderate } \\
\text { pulmonary stenosis, mild pulmonary } \\
\text { insufficiency at } 54.7 \text { mo }\end{array}$ \\
\hline 17 & M & 5.8 & Allograft aortic insufficiency & 11.5 & $\begin{array}{l}\text { Mild neoaortic insufficiency, mild } \\
\text { pulmonary insufficiency at } 43.0 \text { mo }\end{array}$ \\
\hline 20 & M & 12.8 & Allograft aortic insufficiency & 23.4 & $\begin{array}{l}\text { Trace neoaortic insufficiency, moderate } \\
\text { pulmonary stenosis at } 33.9 \text { mo }\end{array}$ \\
\hline 22 & $\mathrm{~F}$ & 8 & $\begin{array}{l}\text { Allograft aortic insufficiency, } \\
\text { mild aortic stenosis }\end{array}$ & 20.6 & $\begin{array}{l}\text { Mild neoaortic insufficiency, trace } \\
\text { pulmonary insufficiency at } 10.4 \text { mo }\end{array}$ \\
\hline 23 & $\mathrm{M}$ & 11 & $\begin{array}{l}\text { Allograft aortic insufficiency, } \\
\text { mild aortic stenosis }\end{array}$ & 22.6 & Intraoperative death \\
\hline \multicolumn{6}{|c|}{ Mechanical valved conduit group $(n=5)$} \\
\hline 3 & M & 0.2 & Allograft aortic insufficiency & 3.3 & Normal valve function at $126.9 \mathrm{mo}$ \\
\hline 13 & $\mathrm{~F}$ & 10.2 & $\begin{array}{l}\text { Allograft aortic insufficiency, } \\
\text { pseudoaneurysm }\end{array}$ & 14.2 & Normal valve function at $53.6 \mathrm{mo}$ \\
\hline $18 \dagger$ & M & 15.1 & $\begin{array}{l}\text { Allograft aortic stenosis, aortic } \\
\text { insufficiency }\end{array}$ & 21.1 & Mild subvalvular stenosis at $42.5 \mathrm{mo}$ \\
\hline 19 & $\mathrm{~F}$ & 12.2 & Allograft aortic insufficiency & 18.8 & Normal valve function at $41.4 \mathrm{mo}$ \\
\hline 21 & M & 11.7 & $\begin{array}{l}\text { Allograft aortic stenosis, } \\
\text { moderate aortic insufficiency }\end{array}$ & 23.3 & Intraoperative death \\
\hline
\end{tabular}

Patients are listed chronologically by group.

* Indicates same patient.

tIndicates same patient. 


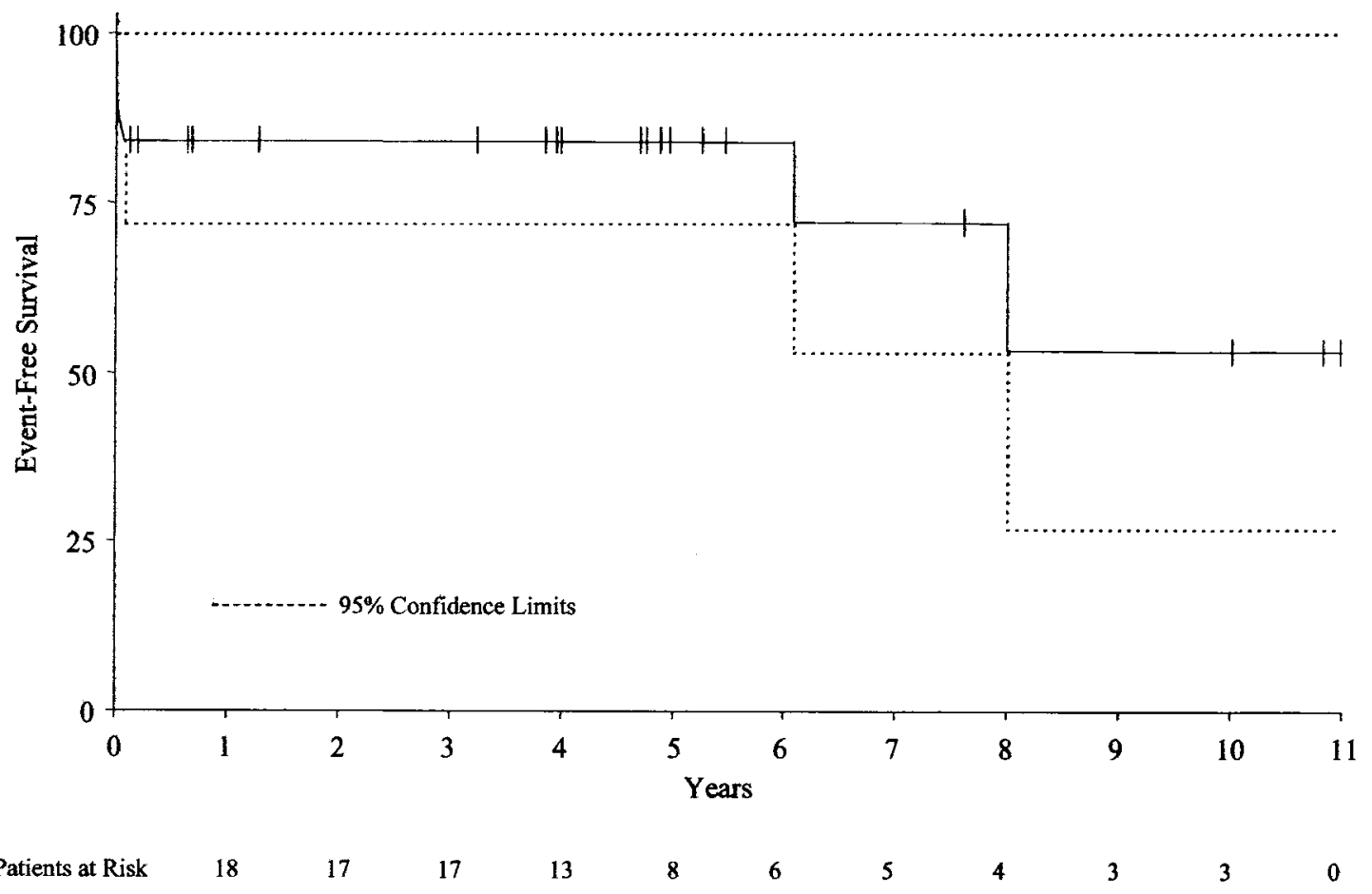

Figure 3. Kaplan-Meier estimated freedom from all valve-related death or event for 25 repeated aortic root replacements performed on 23 patients. Vertical lines indicate censored data.

formed for congenital LVOT disease can be accomplished with good results, considering the inherent complexity in this patient population. Most centers, including our own, now favor the pulmonary autograft whenever feasible for children requiring initial aortic valve replacement. The possibility of autograft growth provides the potential for a lifelong aortic valve replacement that may obviate the need for complex reoperations on the aortic root. ${ }^{15}$ However, the true longevity of the pulmonary autograft in children is unknown.

The overall in-hospital mortality of $8 \%$ in this series is comparable to reports of repeated aortic root replacement in adults, with mortality rates ranging from $3 \%$ to $9 \%$. $^{9-12,16-18}$ Excluding the 2 operative deaths, the 5-year freedom from valve-related death or event was $91 \%$. This series focused on reoperative aortic root replacement in patients whose initial aortic root replacement was performed for congenital LVOT disease, and all patients had undergone previous total allograft aortic root replacement. To our knowledge there are no other published reports concerning similar patients. Furthermore, no other series has included patients with previous extended aortic root replacement.

Yacoub's group ${ }^{9}$ published the only previous article concentrating solely on patients undergoing repeated aortic valve operations after previous total allograft aortic root replacement. Those authors found it possible to perform either mechanical valve replacement or subcoronary allograft replacement within the old allograft conduit in 13 of 22 cases. Because of the porcelainlike allografts frequently encountered, and in some cases size constraints or the presence of active endocarditis, we have not found simple valve insertion (mechanical or subcoronary allograft) feasible in any case. It is possible that either differences in allograft preparation or differences in the response of children to allograft tissue may account for this difference. ${ }^{7}$ Only cryopreserved allografts were used in our patients, in contrast to the fresh, antibiotic-sterilized or "homovital" allografts used by Yacoub's group. ${ }^{9}$ Two additional reports from this group ${ }^{11,19}$ contain patient subpopulations undergoing repeated replacement of the aortic valve after previous allograft aortic valve replacement; however, it is not clear how many (if any) patients had undergone initial total aortic root replacement rather than subcoronary valve implantation. ${ }^{11,19}$

The 2 in-hospital deaths in our series were entirely attributable to technical issues. Others have emphasized the necessity for safe sternal reentry, and our experience further underscores this point. ${ }^{10,12}$ RVOT patch presence increases the risk of right ventricular entry when the previous operation was an extended aortic root replacement. Some authors have advocated routine peripheral cannulation. ${ }^{16}$ However, this strategy has several disadvantages in children. The size 


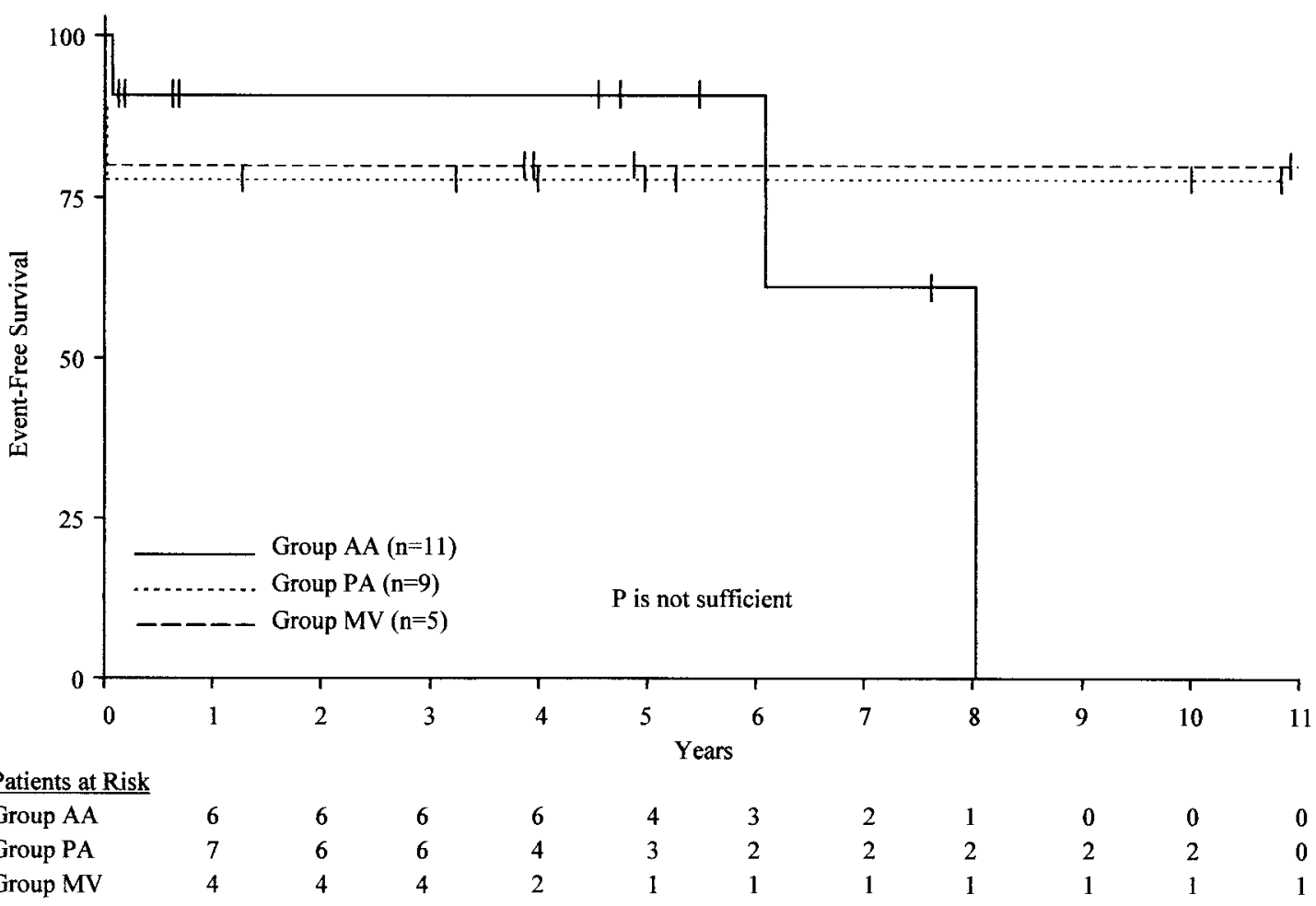

Figure 4. Kaplan-Meier estimated freedom from all valve-related death or event for reoperations with aortic allografts (group $A A$ ), pulmonary autografts (group $P A$ ), and mechanical valved conduits (group MV). There were no statistically significant differences among groups (log-rank test). Vertical lines indicate censored data.

of the femoral vessels in children often necessitates small cannulas that limit perfusion capacity, and vessel injury is also more problematic. Many children have had multiple previous catheterizations at very young ages, producing ileofemoral occlusion. In addition, most patients will require future catheterizations or reoperations, and peripheral vascular access should be preserved. Furthermore, these operations require lengthy cardiopulmonary bypass times, which are significantly extended when bypass is instituted before sternotomy. Lateral chest radiographic findings have been used to assess the safety of sternal reentry. Unfortunately, the retrosternal space of the patient who died of aortic injury during sternal reentry appeared adequate for safe resternotomy. Thoracic computed tomographic scanning is now used routinely to assess the proximity of the aorta and the RVOT to the posterior sternal table (Figure 2). Also, ileofemoral arterial and venous patency is routinely assessed before operation by either catheterization or duplex ultrasonography in all cases. Prophylactic iliac or femoral vessel exposure is achieved before sternotomy in patients deemed at high risk for cardiac or great vessel injury. With this strategy, cardiopulmonary bypass was easily and quickly established in both cases in which right ventricular injury occurred. Establishment of cardiopulmonary bypass with deep hypothermic circulatory arrest before sternotomy should be considered when the risk of aortic entry appears high on the basis of computed tomographic findings. ${ }^{10,17}$ Finally, polytetrafluoroethylene membrane pericardial substitute reduces the risk of cardiac and great vessel injuries at resternotomy and is now placed to reduce the risk of future reoperations.

Few data are available concerning the safety of converting a failed aortic allograft to a pulmonary autograft. A series by Carr-White and coworkers ${ }^{19}$ contains patients who underwent pulmonary autograft aortic root replacement after previous allograft aortic valve replacement. There were no early deaths and no autograft failures. However, the length of follow-up and the number of patients, if any, with previous total aortic root replacement rather than subcoronary allograft implantation were not specified. Conversion to a pulmonary autograft was successful in 7 of 9 cases in our series, and autograft function has been excellent in these 7 patients at a mean follow-up of 68 months. Two of our patients underwent Ross procedures at 4 years of age and have had excellent autograft function without RVOT reoperation for more than 9 years. However, the risk of early autograft failure may be increased. In our experience this problem has not been encountered in patients with previous operations other than extended aortic root replacement. Autograft harvesting is more difficult in the presence of a 
heavily calcified and densely adherent aortic allograft, but autograft injury can usually be avoided by enucleating the autograft without attempting to separate densely adherent allograft tissue. In patients who have had previous extended aortic root replacement, the presence of a heavily calcified or prosthetic RVOT patch in close proximity to the hinge point of the right facing and anterior pulmonary leaflets may not permit an adequate muscular cuff to allow safe use of the autograft. The second death that occurred in our series was from this cause, and careful assessment of the quality of the tissue before committing to the use of the autograft is essential. The etiology of early postoperative autograft failure in our case that required early reoperation is unclear. Intraoperative function was excellent according to transesophageal echocardiography, and the marked autograft edema noted at reoperation remains unexplained. This patient had previously undergone pulmonary artery banding followed by VSD closure with band removal and pulmonary artery reconstruction, with a subsequent operation to close a residual VSD, all before the initial extended aortic root replacement. It is possible that previous interventions on the pulmonary artery may have influenced the quality of the autograft. However, a similar patient who underwent pulmonary artery banding followed by band removal with pulmonary artery reconstruction and then extended aortic root replacement (Table 5, patient 22) had successful conversion to a pulmonary autograft with stable valve function 15 months after a Ross procedure.

There were no predictors of early death or valve failures found among our patients. No predictors of late valverelated events were identified. The retrospective design and relatively small number of patients are significant limitations of the study. The latter problem is magnified for group comparisons. Despite the lack of statistical differences in late outcomes for the three conduit options, we believe that the curve shapes are clinically relevant and that differences will probably emerge with longer follow-up (Figure 4). There is a late decline in freedom from valve-related events in the aortic allograft group, whereas the curves for the pulmonary autograft and mechanical valved conduit groups remain flat after the early postoperative period. The decline in freedom from valve-related death or event for the aortic allograft group is primarily due to late allograft degeneration. This finding is similar to what we have observed in patients undergoing first-time allograft aortic root replacement. ${ }^{8}$ Consequently, pulmonary autograft and mechanical valve longevity may prove superior with further follow-up. Recently the pulmonary autograft has been favored for reoperative patients. Before 1996, aortic allografts were used in 6 cases, pulmonary autografts were used in 2 cases, and a mechanical valved conduit was used in 1 case. Since 1996, pulmonary autografts have been used in 7 of 16 cases, with aortic allografts and mechanical valved conduits used in 5 and 4 cases, respectively. Although differences in age and size among groups were not apparent, this finding was probably due to the low number of patients in the mechanical valved conduit group. Mechanical valves have been used primarily in older patients, in whom anticoagulation is more easily managed.

Conduit selection should be individually tailored. Important considerations include age, sex, medical compliance, ventricular function, presence of infection, previous surgical procedures, physical activity, and patient preference. Allografts remain an option for patients who desire to avoid anticoagulation and in whom either a pulmonary autograft is not feasible or the potential increased risk of early autograft failure is not acceptable. If a pulmonary autograft is chosen, intraoperative findings must ultimately determine whether this option is feasible. Our current practice is to attempt conversion to a pulmonary autograft for patients who are likely to have significant future growth and in whom there is a strong reason to avoid anticoagulation, provided that intraoperative findings allow safe harvesting of the autograft. Repeated aortic allografts are reserved for patients with active endocarditis and patients with a strong reason to avoid anticoagulation but with preoperative or intraoperative findings contraindicating pulmonary autograft. Mechanical valved conduits are favored for patients in whom anticoagulation is acceptable and in whom intraoperative difficulties suggest that this option is the most expeditious means of achieving a safe outcome.

In summary, patients with failed allograft aortic root replacements represent a particularly challenging group. However, our results indicate that repeated aortic root replacement can be accomplished with relative safety after previous standard or extended aortic root replacement with a cryopreserved aortic allograft during childhood. Consequently, patients with failed allograft aortic root replacements should undergo reoperation before deterioration of ventricular dysfunction further complicates the procedure. We have not found simple valve insertion within a failed allograft to be an option in these cases. No differences in 5 -year conduit longevity were detectable among the treatment options. With more patients and longer follow-up, differences are likely to emerge. Late allograft degeneration will probably necessitate further reoperation. Pulmonary autografts are technically more demanding, and there may be an increased risk of early autograft failure in patients who have had previous extended aortic root replacement. However, 5-year autograft function has been stable after successful conversion to a pulmonary autograft.

\section{References}

1. Clarke DR. Extended aortic root replacement for treatment of left ventricular outflow tract obstruction. J Card Surg. 1987;2:121-8. 
2. McKowen RL, Campbell DN, Woelfel GF, Wiggins JW Jr, Clarke DR. Extended aortic root replacement with aortic allografts. J Thorac Cardiovasc Surg. 1987;93:366-74.

3. Konno S, Imai Y, Iida Y, Nakajima M, Tatsuno K. A new method for prosthetic valve replacement in congenital aortic stenosis associated with hypoplasia of the aortic valve ting. J Thorac Cardiovasc Surg. 1975;70:909-17.

4. Rastan H, Koncz J. Aortoventriculoplasty: a new technique for the treatment of left ventricular outflow tract obstruction. J Thorac Cardiovasc Surg. 1976;71:920-7.

5. Somerville J, Ross D. Homograft replacement of aortic root with reimplantation of coronary arteries. Results after one to five years. $\mathrm{Br}$ Heart J. 1982;47:473-82.

6. St Cyr JA, Campbell DN, Fullerton DA, Grosso M, Bishop DA, Clarke DR. Cryopreserved allograft repair of aortic hypoplasia and interrupted aortic arch. Ann Thorac Surg. 1992;53:1110-3.

7. Clarke DR, Campbell DN, Hayward AR, Bishop DA. Degeneration of aortic valve allografts in young recipients. J Thorac Cardiovasc Surg. 1993;105:934-42.

8. Mitchell MB, Campbell DN, Bishop DA, Clarke DR. Aortic allografts for left ventricular outflow tract replacement in children. In: Williams WG, editor. Pediatric cardiac surgery annual of the seminars in thoracic and cardiovascular surgery, vol 3. Philadelphia: WB Saunders; 2000. p. 153-64.

9. Sundt TM 3rd, Rasmi N, Wong K, Radley-Smith R, Khaghani A, Yacoub MH. Reoperative aortic valve operation after homograft root replacement: surgical options and results. Ann Thorac Surg. 1995;60 (2 Suppl):S95-100.

10. Dougenis D, Daily BB, Kouchoukos NT. Reoperations on the aortic root and ascending aorta. Ann Thorac Surg. 1997;64:986-92.

11. Hasnat K, Birks EJ, Liddicoat J, Hon JK, Edwards S, Glennon S, et al. Patient outcome and valve performance following a second aortic valve homograft replacement. Circulation. 1999;100(19 Suppl): II42-7.

12. Raanani E, David TE, Dellgren G, Armstrong S, Ivanov J, Feindel CM. Redo aortic root replacement: experience with 31 patients. Ann Thorac Surg. 2001;71:1460-3.

13. Cabrol C, Pavie A, Gandjbakhch I, Villemot JP, Guiraudon G, Laughlin $\mathrm{L}$, et al. Complete replacement of the ascending aorta with reimplantation of the coronary arteries: new surgical approach. J Thorac Cardiovasc Surg. 1981;81:309-15.

14. Edmunds HL, Clark RE, Cohn LH, Miller C, Weisel RD. Guidelines for reporting morbidity and mortality after cardiac valvular operations. Ann Thorac Surg. 1988;46:257-9.

15. Elkins RC, Knott-Craig CJ, Ward KE, McCue C, Lane MM. Pulmonary autograft in children: realized growth potential. Ann Thorac Surg. 1994;57:1387-94.

16. Hahn C, Tam SK, Vlahakes GJ, Hilgenberg AD, Akins CW, Buckley MJ. Repeat aortic root replacement. Ann Thorac Surg. 1998;66:88-91.

17. Dossche KM, Tan ME, Schepens MA, Morshuis WJ, de la Riviere AB. Twenty-four year experience with reoperations after ascending aortic or aortic root replacement. Eur J Cardiothorac Surg. 1999;16: 607-12.

18. Schepens MA, Dossche KM, Morshuis WJ. Reoperations on the ascending aorta and aortic root: pitfalls and results in 134 patients. Ann Thorac Surg. 1999;68:1676-80.

19. Carr-White GS, Glennan S, Edwards S, Ferdinand FD, Desouza AC, Pepper JR, et al. Pulmonary autograft versus aortic homograft for rereplacement of the aortic valve: results from a subset of a prospective randomized trial. Circulation. 1999;100(19 Suppl):II103-6.

\section{Discussion}

Dr John Hawkins (Salt Lake City, Utah). Dr Mitchell gave an excellent presentation this morning. This group in Denver is to be commended for their excellent results with what I consider one of the more difficult groups of patients that we have to deal with in pediatric cardiac surgery.

The material presented today offers the latest chapter in an ongoing story that this group has been writing, examining the use of the aortic allograft for reconstruction of congenital LVOT obstruction. This is intimately intertwined with the history of The Western Thoracic Surgical Association, and the first chapter was presented here 15 years ago in 1986, when Drs Clarke and Campbell and colleagues in Denver first described the use of the extended aortic root replacement combining cryopreserved allograft aortic root replacement with a Konno-type aortoventriculoplasty in children. The second chapter in this story was presented here 9 years ago at The Western Thoracic Surgical Association in 1992, when the group warned us of the rapid deterioration of aortic allografts in young recipients. The latest chapter, which Dr Mitchell has presented here today, tells us what to expect in terms of short-term and intermediate-term results when replacement of this aortic root allograft needs to be done, and it looks at three different valve replacement options. Although Yacoub's group has described a similar group of reoperations, these primarily have been in adults, and I believe that this is probably the first series of aortic root allograft replacements recorded in the pediatric age group.

There were a total of 25 repeated operations in 23 patients with 2 operative deaths and 2 late deaths, and the long-term actuarial freedoms from death or valve-related events were similar in all three of the treatment options. I have a number of questions.

Dr Mitchell, in the article and the presentation, all the patients but 1 were noted to have severe aortic valve insufficiency at the time of reoperation. I think that 3 or 4 of the patients also had severe aortic allograft stenosis, but in general aortic valve insufficiency was the predominant lesion, and most of the patients did not seem to outgrow their valves. Given the difficulty of quantifying aortic insufficiency, particularly in children, the fact that children often can go many years with moderate degrees of aortic valve insufficiency, and the formidable nature of aortic root replacement, how did you decide when to replace these aortic root allografts? What were your specific indications in terms of aortic insufficiency to replace these allografts?

Dr Mitchell. The honest answer is that it has been a fairly subjective decision. The reality is that most of these patients have had some ventricular dysfunction develop by the time that we have seen them. Largely that has been because the cardiologists have recognized what a formidable group of patients they are and have had the tendency to want to hold back on reoperation in these patients longer than I think should be done. As we have demonstrated, reoperation can be done safely. I really cannot give you a direct answer, other than to say that most other patients have had indications comparable to the indications that we would use in cases of native aortic valve disease.

Dr Hawkins. In Dr Clarke's presidential address, he told us that many of these allografts were taken out piecemeal and that he did not possess enough tissue to furnish us with a picture. We are all aware of the emerging role of immunology in the destruction of these grafts, and we know about the role of calcification and perhaps structural deterioration. Do you have any further data or perhaps insight regarding the pathology in the explanted valves?

Dr Mitchell. We do not have immunologic analyses per se. In 22 of the 25 cases we had the pathologic descriptions, both intraoperative and microscopic. In the vast majority of cases there was severe calcification and fibrosis, with little evidence of any viable tissues other than inflammatory cells in a couple of cases. There were 2 cases in which there was no calcification, and in 
those 2 cases there were inflammatory infiltrates. One of these patients had candidal endocarditis. We saw pseudohyphae and inflammatory cells. The other case was one of the early cases where it was recognized that very young children probably have a different response to allograft tissue, and that was a child who had her reoperation at the age of 3 months. She already had aortic insufficiency, and at that time there was no calcification but there was a non-T-cell lymphocytic infiltrate. This case occurred 12 years ago. No other patients in that young age group have since presented the opportunity to do further sophisticated testing of their pathologic specimens.

Dr Hawkins. The largest group in your division into three groups was the group that had repeated aortic allograft root insertion. These also tended to be in the youngest patients. Given the previous warnings of your group regarding aortic allografts in young patients, why did you decide to replace the failing aortic allograft with another?

Dr Mitchell. I think that decision has to be made on an individual basis. I would say that there has been an evolution toward doing the Ross procedure, and in fact in the last 5 years we have done more Ross procedures in these patients than any other conduit. However, some of these children have active infection, for example, and to add to what is already an extremely difficult case I think would increase the risk. In some cases the pulmonary arteries had been operated on previously. There were a couple of children who had pulmonary artery bands and had then gone back and had pulmonary artery reconstructions. We have actually done Ross procedures in a couple of these patients, 1 of whom was among those with early failure. It is just a much more difficult scenario. There was also 1 patient who was born with truncus arteriosus, so the Ross procedure was not an option.

Dr Hawkins. Finally, among the 9 patients who underwent pulmonary autograft procedures, there were 2 early failures, both in patients who had previously undergone extended aortic root replacement. Do you consider a previous aortic root replacement with a Konno-type aortic ventriculoplasty to be a relative contraindication to doing the pulmonary autograft procedure or just a warning to be more careful in how the autograft is harvested and implanted?

Dr Mitchell. I think it is not a contraindication, but it certainly requires increased discussion with the family in the already difficult situation of choosing a conduit. The bottom line is that the decision has to be made in the operating room. In the case of the patient who died during the operation, we probably should not have proceeded with the Ross procedure. The other case is still a mystery to us. That child had excellent intraoperative function, and when we explanted the autograft the entire thing was edematous, although we could not see any structural surgical damage to the autograft. That patient had a previous pulmonary artery band and reconstruction, so I think that perhaps you have to look at the number of procedures that have been done on the pulmonary artery itself previously and then also see how much adhesion and intraoperative difficulty you encounter, because in some of these cases it has not been that difficult to get the autograft out.

Dr Hawkins. Dr Mitchell, you and your group are to be commended for furthering our understanding of aortic root allografts in children and on your presentation today and your excellent results.

Dr F. Mark Lupinetti (Seattle, Wash). I also congratulate you on your outstanding results with these very challenging operations. They are always quite difficult, but I notice that in your series you describe doing a repeated root replacement I believe in all the cases.

Dr Mitchell. That is correct.

Dr Lupinetti. I wonder if you would consider the classic inclusion technique, because we have found that in these repeated allograft situations it is often quite a bit easier. Especially in the presence of insufficiency, which was the predominant pathologic lesion, an inclusion technique can be done easily and perhaps somewhat more safely, especially when there is concern regarding hemorrhage, dehiscence, or other related problems. Have you ever considered that, or do you think that the root replacement should always be performed?

Dr Mitchell. Can you clarify whether you are referring to the primary or the secondary operation?

Dr Lupinetti. I mean the second operation, after the allograft has failed.

Dr Mitchell. At least in my experience, and I have helped with maybe 6 of these, I would like to see that done, but I do not see how we could have sewn to this tissue. Most of them have required extensive débridement to have anything to sew to, so although I do not say that is not possible, it certainly seems difficult from what I have seen. 